\title{
DUPUYTREN'S CONTRACTURE IN THE FOOT
}

\author{
Report of a Case
}

\author{
T. F. Stoyle, London, England \\ From the Orthopaedic Department, St Bartholomew's Hospital, London
}

A woman of twenty-three had noticed for two years a gradually enlarging nodule in the medial part of the sole of the left foot. It had been intermittently tender on prolonged standing. There was no history of injury. The patient's grandmother had two nodules in the hand.

On examination there was a nodule in the plantar fascia one and three-quarter inches long and a quarter of an inch wide (Fig. 1).

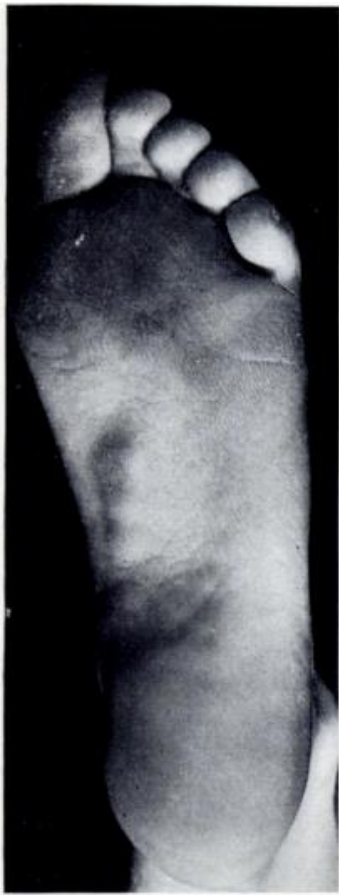

Fig. 1

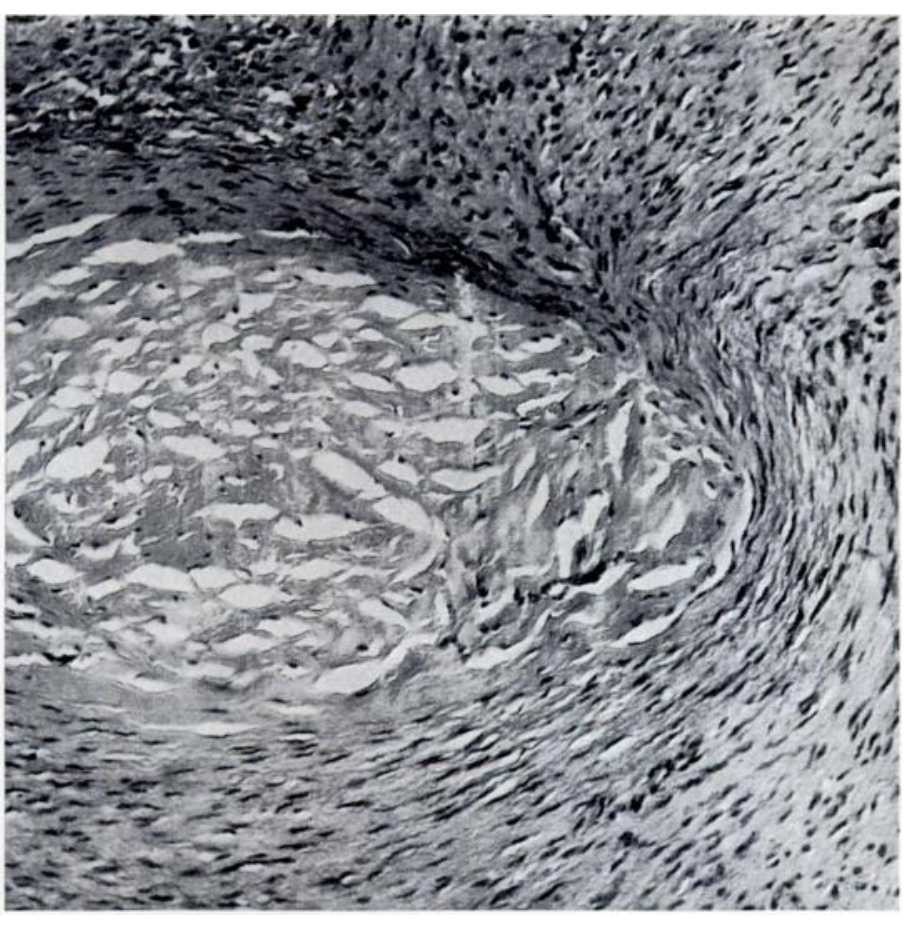

FIG. 2

Figure 1-Photograph to show mass in plantar fascia. Figure 2-Photomicrograph of tissue removed. $(\times 105$.

The fascia of the other sole and of the palms was normal. There was no evidence of Garrod's pads or of any other defect of fibrous tissue.

Operation-The skin was dissected from the lesion to reveal a single firm pearl-coloured non-encapsulated mass, which was excised.

Histology-Sections showed nodules of proliferating fibroblasts intermingled with dense fibrous tissue, characteristic of plantar or palmar fibromatosis (Dupuytren's contracture) (Fig. 2).

\section{DISCUSSION}

Anderson described Dupuytren's disease in the foot in 1891. Though it is well recognised it is uncommon, especially in women. I have not found such a case reported in the British literature. 
Incidence-The literature suggests that a case of Dupuytren's contracture in the foot in a woman might be seen in a large hospital about once every twenty to twenty-five years. Pickren Smith, Stevenson and Stout (1951) found 104 cases of Dupuytren's contracture in the foot and added a further sixteen cases collected from all over the United States. The age of the patients varied from five and a half to sixty years. The sex was recorded in fifty-eight patients; of these only seven were female, a ratio of one in eight. This is the same as the sex ratio in palmar disease (Larsen and Posch 1958). At the Presbyterian Hospital, New York, there were seven cases of plantar disease in twenty years (Pedersen and Day 1954). Luck (1959) discussed the disease in 200 hands and twenty-eight feet.

Etiology-Dupuytren's contracture is familial in 25 per cent of cases (Larsen, Takagishi and Posch 1960, Luck 1959). The disease has an increased incidence among epileptics (Skoog 1948, Early 1962).

Diagnosis-Apart from the patient's age, the case reported is typical of plantar Dupuytren's disease. The mass in the sole is usually under the non-weight-bearing part of the instep. Contracture is not a feature of the disease in the plantar fascia. The tumour may vary in diameter from half a centimetre to several centimetres.

Histology-Superficially the non-encapsulated mass of proliferating fibroblasts presents a similarity to fibrosarcoma. This mistaken diagnosis may be strengthened by the early recurrence of the mass and has led to amputation in some reported cases, mostly those of recurrence after local excision.

Treatment-Total excision of the plantar fascia is advocated by some authorities. Since the condition is known to be benign, this is unnecessarily severe; local excision should be attempted when the lesion is discrete. Total excision of the plantar fascia should be reserved for those cases which recur.

\section{SUMMARY}

1. A case of plantar Dupuytren's disease in a woman aged twenty-three is described.

2. A review of the literature has shown that the histology and rapid recurrence have led to an erroneous diagnosis of fibrosarcoma and treatment by amputation on several occasions.

I wish to thank Mr H. Jackson Burrows for permission to publish this case, Dr A. G. Stansfield for the photomicrograph, and the Department of Medical Photography of St Bartholomew's Hospital for the clinical photograph.

\section{REFERENCES}

Anderson, W. (1891): Lectures on Contractions of the Fingers and Toes; their Varieties, Pathology, and Treatment. (Lecture 1.) Lancet, ii, 1.

Early, P. F. (1962): Population Studies in Dupuytren's Contracture. Journal of Bone and Joint Surgery, 44-B, 602.

LARSEN, R. D., and PosCh, J. L. (1958): Dupuytren's Contracture. Journal of Bone and Joint Surgery, 40-A, 773.

Larsen, R. D., TAKagishi, N., and Posch, J. L. (1960): The Pathogenesis of Dupuytren's Contracture. Journal of Bone and Joint Surgery, 42-A, 993.

LuCK, J. V. (1959): Dupuytren's Contracture. Journal of Bone and Joint Surgery, 41-A, 635.

Pedersen, H. E., and Day, A. J. (1954): Dupuytren's Disease of the Foot. Journal of the American Medical Association, 154, 33.

Pickren, J. W., Smith, A. G., Stevenson, T. W., Jnr., and Stout, A. P. (1951): Fibromatosis of the plantar fascia. Cancer, 4, 846.

SKooG, T. (1948): Dupuytren's Contraction, with Special Reference to Aetiology and Improved Surgical Treatment; its Occurrence in Epileptics; note on Knuckle-pads. Acta Chirurgica Scandinavica, 96, (Supplement 139), 1. 